\title{
Solution of an ELD problem with valve-point effect using artificial intelligence techniques
}

\author{
Ansil Sharma, Govind R. Goyal* \\ Vivekananda Global University, Jaipur 303012, India \\ Email: er.grgoyal@gmail.com
}

\begin{abstract}
This research paper gives solution for Economic Load Dispatch (ELD) problem with considering valve point effect. ELD is the oldest and most important problem of optimal power flow. Objective of the ELD problems is to find out the optimal combination of power outputs of generating units so as to cope up the load demand at minimum cost while satisfying all the equality and inequality constraints. Conventionally, the function of cost for each unit in ELD problems has been approximately represented by a quadratic equation and is solved using various conventional and artificial intelligent techniques of optimization. Unfortunately, high non-linearity is present in the input-output characteristics of generating units' due to presences of prohibited operating zones, valve point loading effects, and multi-fuel effects, etc. Thus, the practical ELD problem is formulated as optimization problem of a non-smooth function with equality and inequality constraints, which cannot be solved by the conventional optimization methods. The performance of Cuckoo Search method and PSO with some modifications is tested on a standard test bed system i.e. IEEE 30-bus 6-generators system.
\end{abstract}

Keywords: Valve-point Effect, Cuckoo Search Method (CS), Modified PSO (MPSO).

\section{INTRODUCTION}

The prime responsibility of a power engineer is to maintain economy and continuity of power supply. So that electrical power systems are designed and operated in order to meet the highly dynamic demands of various types of loads. Economic Load Dispatch (ELD) is a method to schedule the generator's power outputs with respect to the load demands in order to minimize of the operational cost, and to operate the power system most economically. Over the years, many efforts have been made to solve the Economic Load Dispatch (ELD) problem, incorporating different kinds of constraints or multiple objective functions through various mathematical programming and optimization techniques. Various algorithms available for optimizations are broadly classified into conventional methods and swarm intelligence based AI techniques. The conventional methods include NewtonRaphson (NR) method, Lambda Iteration method (LIM), Base Point and Participation Factor method, Gradient Point (GP) method, etc[1]. However, these classical strategy of optimal power dispatch require to consider the incremental cost curves to be monotonically increasing or it should be piece-wise linear[2]. In this paper non-smooth function of ELD is considered which shows the input-output characteristics of modern generating units. These curves are highly non-linear (with valve-point effect and rate limits etc.) and having multiple local optimum points in the cost function. The objective function of ELD problem with valve-point effect is not a linear one and it is non-differential too[15]. These functions are valued by classical dispatch algorithms which resulted in huge revenue loss over the time. Consideration of non-linearity in cost functions of generating units requires highly robust algorithms to avoid getting stuck at local optimum solutions[3]. In this respect, stochastic search algorithms like Genetic Algorithm (GA)[9], Evolutionary Strategy (ES)[12], Evolutionary Programming (EP)[2-3,13], Particle Swarm Optimization (PSO)[18] and Simulated Annealing (SA) may prove to be very efficient in solving highly nonlinear ELD problem without any restrictions on the shape of the cost curves. Although, these heuristic methods do not always guarantee the global optimal solution, they generally provide a fast and reasonable solution (sub optimal or near global optimal).

Recently a new evolutionary technique i.e. Cuckoo Search method (CS) has been introduced in 2009 by Xin-She Yang, this algorithm is encouraged by brooding behaviour of cuckoo birds. This algorithm can take care of optimality on rough and discontinuous surface[20]. It can handle integer and discrete optimization problems efficiently. This algorithm is easy to implement on any optimization problem because of it has less number of control variables[14,20]. The CS algorithm has been used as an optimization tool in solving various single and multi-objective OPF problems[15-16]. Second technique is particle swarm optimization (PSO) which has been used to solve various engineering problems[18-22]. This paper proposes two evolutionary optimization techniques namely Cuckoo Search (CS) method and Modified PSO (MPSO) to solve ELD for the electric power system. Above two 
techniques are respectively used to solve an ELD problem with valve point effect for IEEE 30 bus standard system and the comparison between results obtained by above two methods has been presented.

\section{PROBLEM FORMULATION}

\section{A. Problem objectives}

\section{Function of fuel cost without valve-point effect}

The generating cost of any plant is the cost of fuel required to generate electric power in order to meet the power demand and power losses in the system. Economic dispatch (ED) problem is to be considered as minimization of total generating cost $\mathrm{Ci}$, by varying the generated power output $\mathrm{P}_{\mathrm{g}}$ from each unit within its min-max limits. Here, total generating cost $\mathrm{Ci}$, is the function defined in terms of the power generated, represented as[3]

The fuel cost of any generator unit $\mathrm{i}$ can be represented as quadratic equation of real power generated Pgi as follows:

$$
C_{i}=a_{i} P g_{i}^{2}+b_{i} P g_{i}+c_{i}(\$ / h)
$$

where, $a_{i}, b_{i}, c_{i}$ is fuel cost coefficients of ith unit.

\section{Function of fuel cost with valve-point effect}

Input-output characteristic of any generating unit is approximated using quadratic cost function, under the assumption that the "incremental fuel cost curve of the power generating units are monotonically increasing piecewise-linear functions". However, the real input-output characteristics displays higher-order nonlinearities and discontinuities present in curve due to valve-point effect in fossil fuel burning power plants. The valve-point effects introduce ripples in the heat-rate curves.

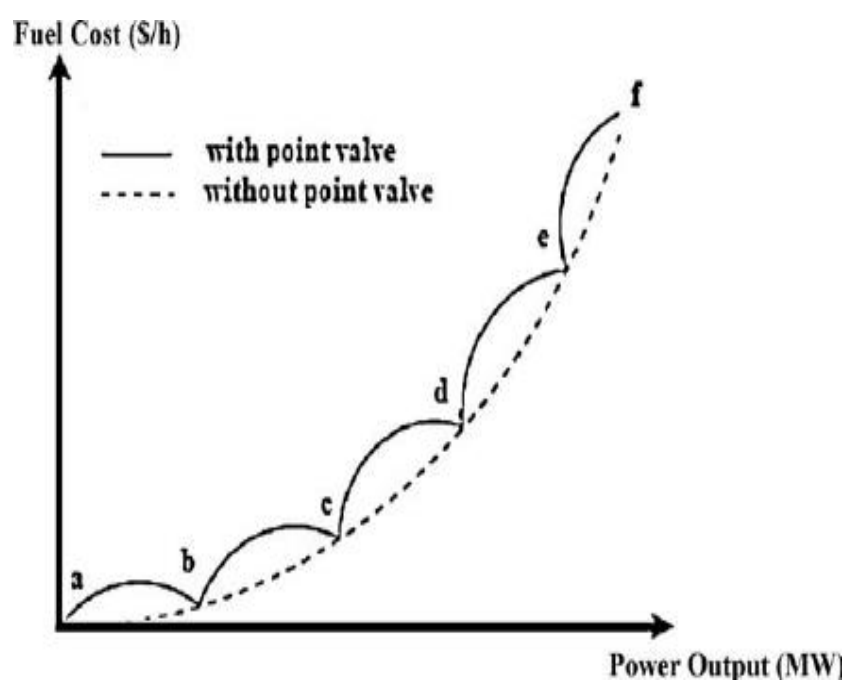

Figure 1. Fuel-Cost curve with and without valve point effect

The valve-point loading effect has been demonstrated in a periodic rectified sinusoidal function. Mathematically, economic load dispatch problem considering valve point loading is defined as following:
$F\left(P_{i}\right)=\sum_{i=1}^{N G}\left(a_{i} P_{i}^{2}+b_{i} P_{i}+c_{i}+\left|d_{i} * \sin \left\{e_{i}^{*}\left(P_{i}^{\min }-P_{i}\right)\right\}\right|\right)$

where- $a_{i}, b_{i}, c_{i}, d_{i}, e_{i}$ are the cost co-efficient of the ith generating unit.

\section{B. System constraints}

In this paper following equality and inequality constraints are considered:

\section{1) Equality constraints}

Real power balance i.e. total generation should be equal to total demand plus losses, is to be considered as equality constraint [13].

$\sum_{i=1}^{N G} P g_{i}-\sum_{i=1}^{N B} P d_{i}-$ Ploss $=0$

Here, NG is no. of generating units and NB is the number of load buses. Pg is the active power generated; Pd is the active power load.

Ploss denotes active power loss in power system network. Transmission losses may vary from 5 to $15 \%$ of total load. It is very important to calculate transmission losses while solving an economic load dispatch (ELD) problem.

$$
\text { Ploss }=\sum_{k=1}^{N L} g_{k}\left[\left|V_{i}\right|^{2}+\left|V_{j}\right|^{2}-2\left|V_{i} \| V_{j}\right| \cos \left(\delta_{i}-\delta_{j}\right)\right]
$$

\section{2) Inequality Constraints}

Generator power output limits, minimum and maximum limits are to be considered as inequality constraints.

$$
P g_{i}^{\min } \leq P g_{i} \leq P g_{i}^{\max }
$$

Here NG shows the number of generators, $(i=1,2 \ldots . . \mathrm{NG})$ A penalty factor, $\mathrm{K} 1$ is used in the formation of objective function for ELD problem considering equality constraints (power balance equation). The value of $\mathrm{K} 1$ is optimized by trial base method. If the power balance equation is not satisfied than it will be charged a penalty and that particular solution will be sorted out. But, if the solution given by the algorithm satisfies the equality constraint than, power balance equation will becomes equal to 0 and there is no effect of penalty factor.

\section{SWARM INTELLIGENCE BASED ALGORITHMS}

Cuckoo search method

\section{1) Overview}

Cuckoo Search (CS) method is one of the recent developed meta-heuristic algorithms. This method is based on breeding behaviour of bird's family named as "Cuckoo". It's similarity with the working behaviour of cuckoo birds which is based on brooding parasitism, this algorithm also works in order to find most suitable host nest.

2) Cuckoo Breeding Behaviour 
Cuckoo Search method works on basics of the breeding behaviour of cuckoo birds. Cuckoo is a family of birds like Ani and Guira found in various regions of all over the world. It is named as cuckoo because of the sweet sound it makes. Brooding behaviour of cuckoo birds is very different. These birds lay their eggs in communal nests because of their eggs are same in colour.

Population generation in Cuckoo Search is similar to other evolutionary algorithms. The initial population is generated randomly within the min-max limits of control parameter. Then the Levy flight operator is performed on all individuals.

\section{3) Levy flights}

Levy flight is an operator which shows the characteristics of flight behaviour of cuckoo birds. Levy flights provide a random walk with step size ' $\alpha$ ', and this step size is decided by Levy Distribution[20]

$\operatorname{Levy}(\lambda)=\mathrm{t}^{\lambda}$

$\alpha=0.01 * \mathrm{~s}(\mathrm{X}-\mathrm{Gbest})$

Here, $\lambda$ is the "skew parameter" which can be in the range of 1 to 3. It can have infinite variance with infinite mean[21].

$$
\sigma_{u}=\left\{\frac{\Gamma(1+\beta) \sin (\pi \beta / 2)}{\Gamma[(1+\beta) / 2] \beta 2^{(\beta-1) / 2}}\right\}^{1 / \beta}
$$

\section{4) Random walks}

It is well known that randomization carried out by "Random Walks" and "Heavy tailed Walks". Random walk is a random process which consists of a series of random steps. It obeys the Gaussian distribution. If consecutive steps are denoted by $\mathrm{Xi}(\mathrm{i}=1,2,3,4 \ldots \ldots \mathrm{N})$ and their sum is $\mathrm{S}_{\mathrm{N}}$ which denotes an $\mathrm{N}$ dimensional random walk [16].

$\mathrm{S}_{\mathrm{N}}=\sum \mathrm{X}_{\mathrm{i}}=\mathrm{X}_{1}+\mathrm{X}_{2}+\ldots \ldots . . \mathrm{X}_{\mathrm{N}}$

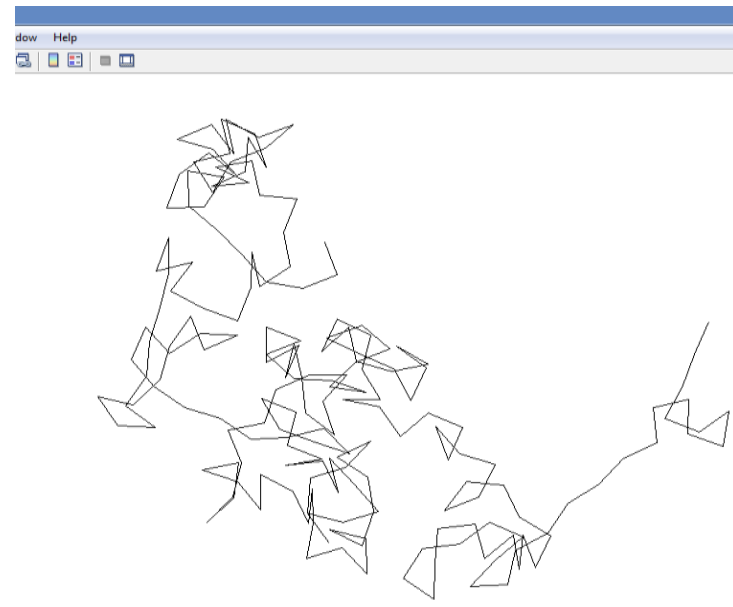

Figure 2. X-Y Plot for levy flights

\section{5) Steps of Cuckoo Search}

On behalf of the CS algorithm's theory we have the following idealized rules[1]:

1. The number of host nests and Cuckoos kept constant.
2. Each Cuckoo can lay single or multiple eggs at a time and dumps it in a randomly chosen nest.

3. The best nests with high quality eggs will be passed over to the next generation.

4. The probability of getting identified the eggs laid by cuckoo by host, is $\mathrm{Pa}$ which lie in the range of $[0,1]$.

As the all evolutionary algorithms, CS also starts with some initial population.

$X_{i}=X_{i}^{\min }+\operatorname{rand}()^{*}\left(X_{i}^{\max }-X_{i}^{\min }\right)$

$(i=1,2 \ldots N P)$ Where, $i$ is the number of eggs.

Vector $\mathrm{X}^{\mathrm{t}+1}$ represent new solutions generated from the present set of solutions $\mathrm{X}^{\mathrm{t}}$, with the help of Levy walks.

$X^{t+1}=X^{t}+\alpha \oplus \operatorname{Levy}(\lambda)$

Here, $\alpha$ is the step size. It can vary between $0.1-1.0[14]$. The symbol $\oplus$ shows element vice multiplication.

\section{MODIFIED PARTICLE SWARM OPTIMIZATION MPSO}

\section{1) Overview}

Particle Swarm Optimization (PSO) algorithm was first described in 1995 by J. Kennedy and R. C. Eberhart This algorithm is inspired by simulation of social psychological expression. As like people solve their problems by talking with each other and interacts by sharing their beliefs, attitudes, and behaviour changes. In PSO, each individual makes its decisions by his own experience together with other's experiences. The algorithm of PSO works in a way to have all the particles being located in the optimal position.

PSO is an efficient Evolutionary Algorithm (EA) which is inspired by the social flocking behaviour of birds and the schooling behaviour of fish. All the particles in the PSO fly through problem space. Thus, working behaviour of swarm intelligent techniques is based on three important factors:

1. Cohesion-Stick together.

2. Separation-doesn't come too close.

3. Alignment - Follow the general heading of the flock.

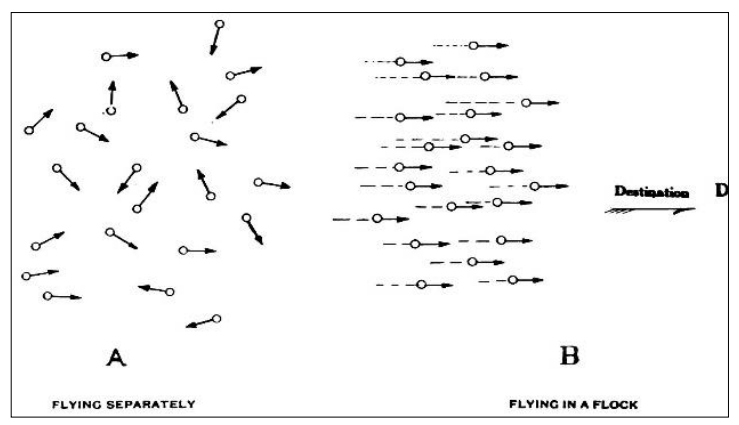

Figure 3. Flight's behaviour of PSO

\section{2) Initialization}

As like other evolutionary algorithms, PSO is also initialized with some random solutions. In PSO, each 
individual "i", called particle, represents a solution to the optimization problem i.e. a vector of decision variables, $\mathrm{X}_{\mathrm{i}}[13]$.

$$
X_{i}=X_{i}^{\min }+\operatorname{rand}()^{*}\left(X_{i}^{\max }-X_{i}^{\min }\right)
$$

Here, NP shows the number of particles, $(i=1,2 \ldots . . N P)$

\section{3) Update the solution vector}

In PSO algorithm particles follow the fittest member of the swarm and move toward historically good areas of the provided space. Each particle tries to modify its position using the following information:

1 Current positions,

2 Current velocities,

3 Difference of current position and individual position

4 Difference of current position and global best position

In order to modify the solutions vector, each individual is associated with some velocity, v. Starting from some random value, velocity is updated in each iteration by the following equation [13]

$v_{i j}^{t+1}=w v_{i j}^{t}+c_{1} R_{1}\left(\right.$ Pbest $\left.^{t}-X^{t}\right)+c_{2} R_{2}\left(\right.$ Gbest $\left.^{t}-X^{t}\right)$

Gbest is the global best position in the problem space. Pbest is the best known individual position of a particle.

$\mathrm{V}_{\mathrm{ij}}^{\mathrm{t}}$ is velocity of $\mathrm{jth}$ member of ith particle at iteration number $t$ which is bounded in its min-max limits[18]

$v_{j}^{\min } \leq v_{i j} \leq v_{j}^{\max }$

$\mathrm{R}_{1} \& \mathrm{R}_{2}$ are the random numbers generated between 0 and 1 . On the other hand, $\mathrm{C}_{1} \& \mathrm{C}_{2}$ can vary in range of 0-4 but these are adjusted such as sum of $\mathrm{C}_{1}$ and $\mathrm{C}_{2}$ should be 4 . Here $\mathrm{C}_{1}=\mathrm{C}_{2}=2[12]$.

$\mathrm{W}$ is inertia-weight which is given as follows:

$w=w^{\max }-\frac{\left(w^{\max }-w^{\min }\right) * \text { iteration }}{\max \text { iteration }}$

At each iteration the position vector of swarms is updated by adding the velocity ' $\mathrm{v}$ ' in the current solution vector and same processes is repeated as shown in flowchart of MPSO[18].

$X^{t+1}=X^{t}+v^{t+1}$

\section{4) Constriction Factor}

To reduce velocity clamps and boosting convergence, a constriction factor, $\mathrm{k}$ proposed by Kennedy[12] which lie in interval of 0.5 to $1.0[11]$.

$$
v_{i j}^{t+1}=k^{*}\left\{w v_{i j}^{t}+c_{1} R_{1}\left(\text { Pbest }^{t}-X^{t}\right)+c_{2} R_{2}\left(\text { Gbest }^{t}-X^{t}\right)\right\}
$$

\section{SIMULATION STUDY \& RESULTS}

a) System under study

The proposed algorithms are implemented and tested on a standard test bed of IEEE- 30 bus 6-generators system. IEEE 30 bus power system consists of 48 branches, 6 generating units (generator buses) and 22 load-buses. Here, Bus-1 is considered as slack bus, on the other hand generators are connected on bus number: 2,5,8,11,13 and remaining others are PQ-buses.

Table 1. Fuel cost coefficients of system

\begin{tabular}{|c|c|c|c|c|c|}
\hline Unit & $\mathbf{a}$ & $\mathbf{b}$ & $\mathbf{c}$ & $\mathbf{d}$ & $\mathbf{e}$ \\
\hline 1 & 0.0015 & 1.8 & 40 & 200 & 0.035 \\
\hline 2 & 0.0030 & 1.8 & 60 & 140 & 0.040 \\
\hline 5 & 0.0012 & 2.1 & 100 & 160 & 0.038 \\
\hline 8 & 0.0080 & 2.0 & 25 & 100 & 0.042 \\
\hline 11 & 0.0010 & 2.0 & 125 & 180 & 0.037 \\
\hline 13 & 0.0625 & 1.0 & 80 & 120 & 0.025 \\
\hline
\end{tabular}

Table 2. Parameters of CS and MPSO set for OPF

\begin{tabular}{|c|c|c|}
\hline S. No. & Parameter & Value \\
\hline 1 & No. of Cuckoo Nests (n) & 30 \\
\hline 2 & Discovery rate of Cuckoo Eggs (pa) & $1 / 4^{\text {th }}$ \\
\hline 3 & No. of Particles in PSO (N) & 30 \\
\hline 4 & No. of Variables in CS \& PSO (D) & 06 \\
\hline 5 & Penalty factor in CS \& PSO (k) & 10 \\
\hline 6 & Max Iterations for CS & 500 \\
\hline 7 & Max Iterations for PSO & 300 \\
\hline 8 & Constriction Factor in MPSO & 0.5 \\
\hline
\end{tabular}

Table 3. Solutions for ELD without valve-point effect

\begin{tabular}{|c|c|c|c|c|c|}
\hline \multirow{2}{*}{ S. No. } & \multirow{2}{*}{$\begin{array}{c}\text { Paramete } \\
\mathbf{r}\end{array}$} & $\begin{array}{c}\text { Load } \\
\text { Flow }\end{array}$ & CS & PSO & MPSO \\
\cline { 3 - 6 } & $\operatorname{Pg} 1$ & $\begin{array}{c}104.6 \\
2\end{array}$ & $\begin{array}{c}137.5 \\
47\end{array}$ & 111.676 & 120.727 \\
\hline 2 & $\operatorname{Pg} 2$ & 80.00 & $\begin{array}{c}54.03 \\
9\end{array}$ & 76.487 & 64.445 \\
\hline 3 & $\operatorname{Pg} 5$ & 50.00 & $\begin{array}{c}40.23 \\
4\end{array}$ & 47.743 & 49.618 \\
\hline 4 & $\operatorname{Pg} 8$ & 20.00 & $\begin{array}{c}31.58 \\
0\end{array}$ & 13.428 & 12.835 \\
\hline 5 & $\operatorname{Pg} 11$ & 20.00 & $\begin{array}{c}16.98 \\
9\end{array}$ & 27.643 & 29.998 \\
\hline 6 & Pg13 & 20.00 & $\begin{array}{c}12.70 \\
0\end{array}$ & 17.852 & 15.741 \\
\hline 7 & $\begin{array}{c}\text { Total Gen. } \\
(\text { MW) }\end{array}$ & $\begin{array}{c}294.6 \\
2\end{array}$ & $\begin{array}{c}294.9 \\
3\end{array}$ & 294.832 & 294.36 \\
\hline 8 & $\begin{array}{c}\text { Cost of } \\
\text { Gen. (\$/h) }\end{array}$ & $\begin{array}{c}\mathbf{1 0 3 4} \\
\mathbf{5 2 4}\end{array}$ & $\begin{array}{c}\mathbf{1 0 2 9} \\
\mathbf{5 4 3}\end{array}$ & $\mathbf{1 0 2 9 . 3 2 9}$ & $\mathbf{1 0 2 4 . 0 6}$ \\
\hline
\end{tabular}


In this paper, programs have been developed using MATLAB-2013 to demonstrate the effectiveness of Cuckoo search (CS), Particle Swarm Optimization (PSO) and
Modified PSO for optimal active power dispatch problem with and without valve point function on IEEE 30 bus system.

Table 4. Solutions for ELD with valve-point effect

\begin{tabular}{|c|c|c|c|c|c|}
\hline \multirow{2}{*}{ S. No. } & \multirow{2}{*}{ Parameter } & \multicolumn{4}{|c|}{ Based on } \\
\cline { 2 - 6 } & Load Flow & CS & PSO & MPSO & \multicolumn{1}{|c|}{142.977} \\
\hline 1 & $\operatorname{Pg} 1$ & 104.62 & 137.137 & 143.864 & 75.273 \\
\hline 2 & $\operatorname{Pg} 2$ & 60.00 & 36.998 & 18.430 & 18.462 \\
\hline 3 & $\operatorname{Pg} 5$ & 19.224 & 14.864 & 13.878 \\
\hline 4 & $\operatorname{Pg} 8$ & 20.00 & 26.885 & 28.078 & 29.612 \\
\hline 5 & $\operatorname{Pg} 11$ & 20.00 & 12.072 & 14.865 & 13.180 \\
\hline 6 & $\operatorname{Pg} 13$ & 20.00 & 294.187 & 294.393 & 294.384 \\
\hline 7 & Total Gen. (MW) & 294.615 & $\mathbf{1 0 5 6 . 7 2 5}$ & $\mathbf{1 0 5 8 . 5 3 5}$ & $\mathbf{1 0 4 2 . 8 7 8}$ \\
\hline 8 & Cost of Gen. (\$/h) & $\mathbf{1 0 9 7 . 0 8 6}$ & &
\end{tabular}

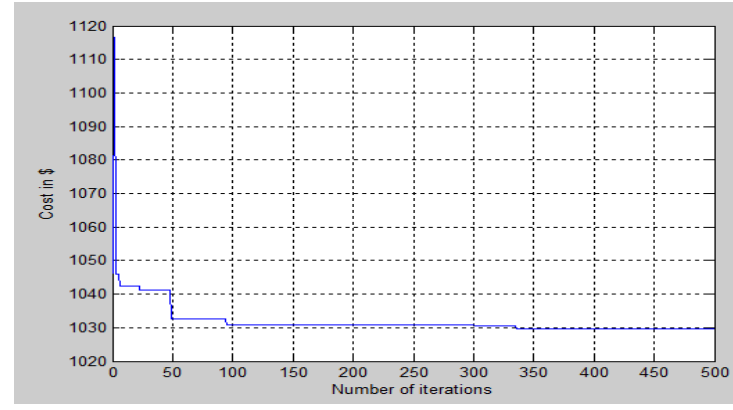

Figure 4 Fitness curve for ELD without valve-point effect by Cuckoo Search

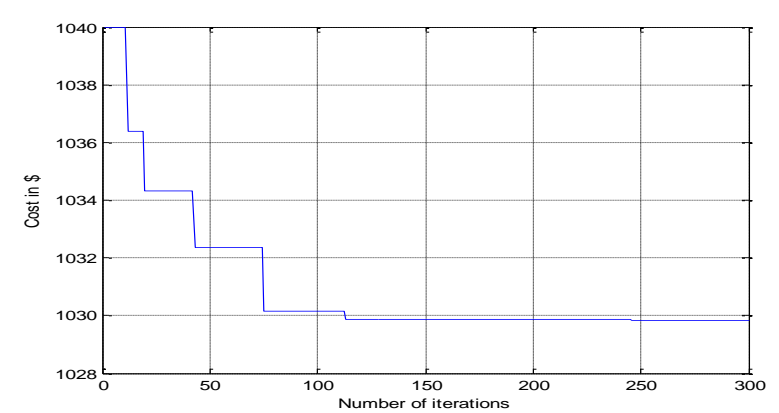

Figure 5. Fitness curve for ELD without valve-point effect by PSO

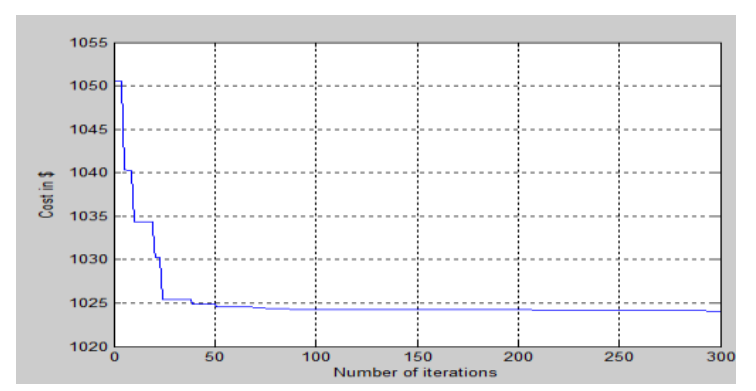

Figure 6. Fitness curve for ELD without valve-point effect by Modified PSO

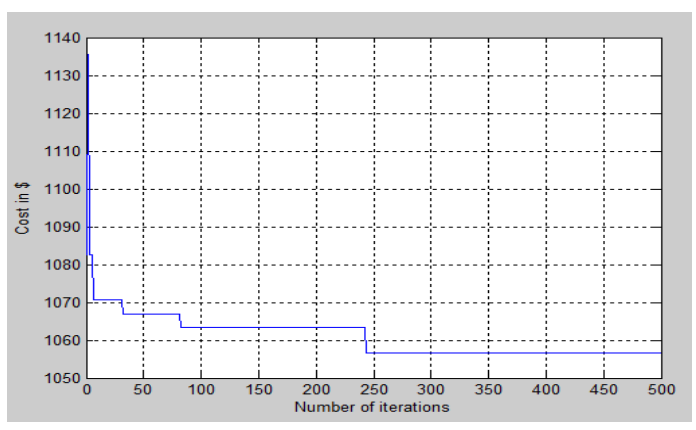

Figure 7. Fitness curve for ELD with valve-point effect by CS

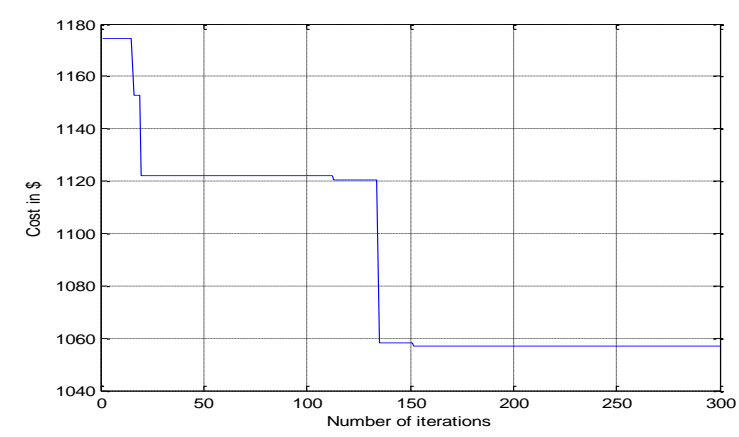

Figure 8. Fitness curve for ELD with valve-point effect by PSO

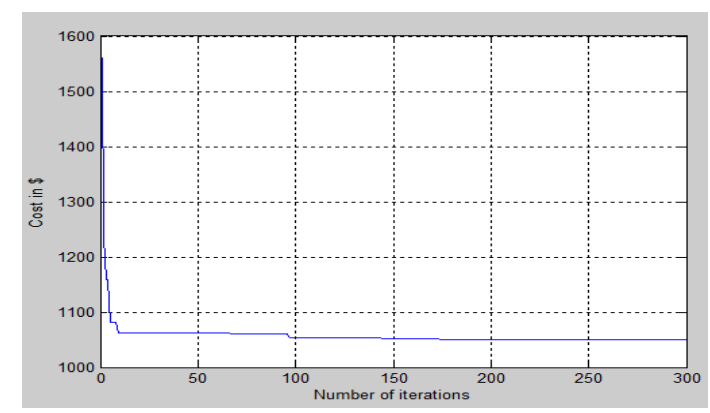

Figure 9. Fitness curve for ELD with valve-point effect by Modified PSO 


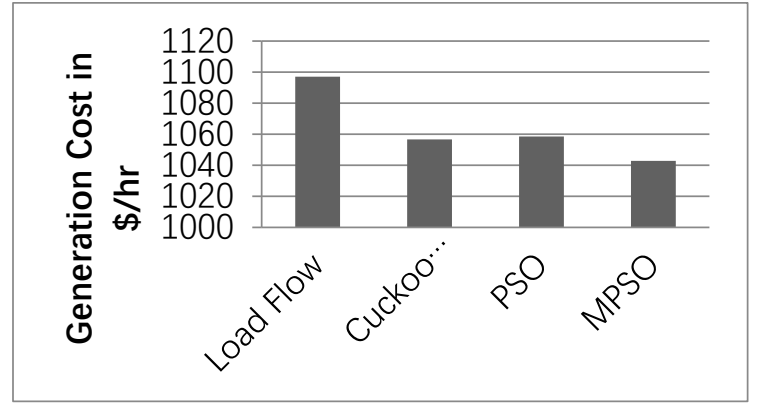

Figure 10. Comparison for ELD with valve point by various optimization techniques for IEEE 30 bus system

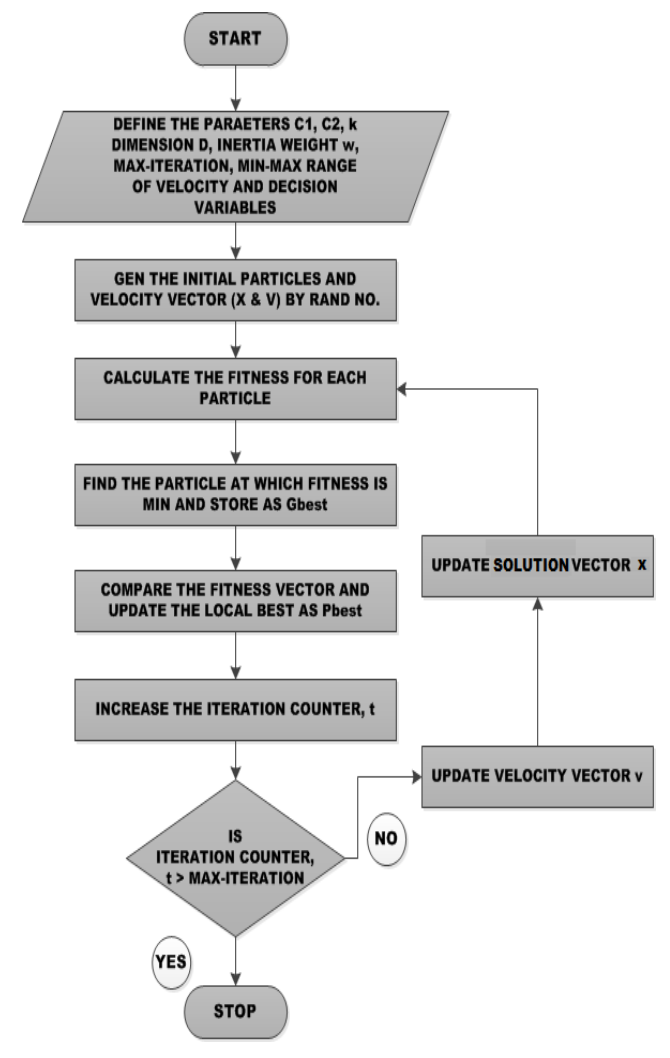

Figure 11. Flowchart for process of modified PSO technique

\section{CONCLUSION}

This paper shows the performance of Cuckoo search (CS) and Modified PSO in solving ELD problem with and without valve point effect. Proposed approach is simulated and tested on standard IEEE 30 bus 6 generators system. For case of economic load dispatch (ELD) with valve point effect, best solution was obtained by Modified PSO technique; it minimized generation cost by $4.94 \%$ as compared to initial load flow solutions. On other hand Cuckoo search method minimized fuel cost by $3.68 \%$ for the same case. The simulation results show the effectiveness of Cuckoo search method and Modified PSO techniques in handling of nonsmooth function of optimal active power dispatch problem. Comparative analysis of performance by various AI techniques demonstrates that the proposed Modified PSO method can avoid the shortcoming of premature convergence.

\section{REFERENCES}

[1] Aganagic M., et al. (1997). Economic dispatch with generation contingency constraints, IEEE Transactions on Power Systems, Vol. 12, pp. 1229-1236.

[2] Kenji I. (1994). Reactive power optimization by genetic algorithm, IEEE Transactions on Power Systems, Vol. 9, No. 2.

[3] Gaing Z.L. (2003). Particle swarm optimization to solving the economic dispatch considering the generator constraints, IEEE Transactions on Power Systems, Vol. 18, No. 3, pp. 1187-95.

[4] Lee K.Y., El-Sharkawi M.A. (2002). Modern heuristic optimization techniques with applications to power systems, IEEE Power Engineering Society.

[5] Sinha N., Chakrabarti R., Chattopadhyay P.K. (2003). Evolutionary programming techniques for economic load dispatch, IEEE Transactions on Evolutionary Computation, Vol. 7, pp. 83-94.

[6] Ling S.H. et al. (2003). Improved genetic algorithm for economic load dispatch with valve-point loadings, Industrial Electronics Society, IECON '03. The 29th Annual Conference of the IEEE, Vol. 1, pp. 442-447.

[7] Park J.B., Lee K.S., Shin J.R., Lee K.Y. (2005). A particle swarm optimization for economic dispatch with non-smooth cost functions, IEEE Trans. On Power System, Vol. 20, No. 1, pp. 34-42.

[8] Jong B.P., Song L.K., Rin S.J., Lee K.Y. (2005). A particle swarm optimization for economic dispatch with non-smooth cost functions, IEEE Transactions on Power Systems, Vol. 20, pp. 34-42.

[9] Kim K.S., Jung L.H., Lee S.C. (2007). Security constrained economic dispatch using interior point method, International Conference on Power System Technology, 1-4244-0111-9/06/IEEE, pp. 1-6.

[10] Park J.B., Jeong Y.W., Lee W.N., Shin J.R. (2006). An improved particle swarm optimization for economic dispatch problems with non-smooth cost functions, IEEE Trans.

[11] Selvakumar A.I., Thanushkodi K. (2007). A new particle swarm optimization solution to non-convex economic dispatch problems, IEEE Transactions on Power Systems, Vol. 22, pp. 42-51.

[12] Kumar K.S., Tamilselvan V. et al. (2008). Economic load dispatch with emission constraints using various PSO algorithms, WSEAS Transactions on Power System, Vol. 3, No. 9.

[13] Chaturvedi K.T. et al. (2008). Particle swarm optimization with crazy particles for nonconvex economic dispatch, Journal of Applied Soft Computing (Elsevier). DOI: 10.1016/j.asoc.2008.11.012

[14] Kumar K.S., Rajaram R., Tamilselvan V., Shanmugasundaram V., Naveen S., Nowfal I.G.M. (2009). Economic dispatch with valve points effect using various PSO techniques, International Journal of Recent Trends in Engineering, Vol. 2, p. 6.

[15] Amita M., Vishnu P., Saroj R. (2009). Economic dispatch using particle swarm optimization: A review, Journal of Renewable and Sustainable Energy Reviews (Elsevier). DOI: 10.1016/j.rser.2009.03.007

[16] Mehdi N., Malihe M.F. (2010). Hossein nezamabadipour, "A modified particle swarm optimization for economic dispatch with non-smooth cost functions, Journal of Engineering Applications of 
[17] Artificial Intelligence (Elsevier), DOI: 10.1016/j.engappai.2010.06.006

[18] Basu M., Chowdhury A. (2013). Cuckoo search algorithm for economic dispatch, Journal of Energy (Elsevier), Vol. 60, No. C, pp. 99-108. DOI: 10.1016/j.energy.2013.07.011

[19] Basu M. (2015). Modified particle swarm optimization for non-convex economic dispatch problems, Journal of Electrical Power and Energy Systems (Elsevier), DOI: $10.1016 /$ j.ijepes.2015.01.015

[20] Vijay K.J., Nikhil G. Niazi K.R., Anil S. (2015). Modulated particle swarm optimization for economic emission dispatch, Journal of Electrical Power and
Energy Systems (Elsevier), DOI: 10.1016/j.ijepes.2015.04.004

[21] Goyal G.R., Mehta H.D. (2015). Optimal dispatch of active and reactive power using cuckoo search method, IJIREEICE, DOI: 10.17148/IJIREEICE.2015.3204

[22] Govind R.G., Mehta H.D. (2015). Multi-objective optimal active power dispatch using swarm optimization techniques, 5th Nirma University International Conference on Engineering (NUiCONE), 978-1-4799-9991-0/15/\$31.00 @2015 IEEE.

[23] Vaseem K.S., Govind R.G., Mohammad A.K. (2015). Economic generator scheduling using newton-raphson method, IJAREST, Vol. 2, No. 4. 